\title{
Comparing global models of terrestrial net primary productivity (NPP): analysis of the seasonal atmospheric $\mathrm{CO}_{2}$ signal
}

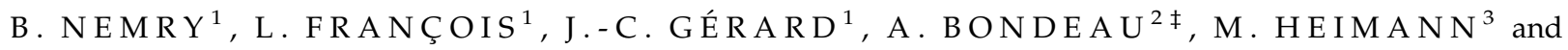 \\ THE PARTICIPANTS OF THE POTSDAM NPP MODEL INTERCOMPARISON* \\ ${ }^{1}$ Laboratoire de Physique Atmosphérique et Planétaire (LPAP), Institut d'Astrophysique et de Géophysique, Université de Liège, \\ B-4000 Liège, Belgium, ${ }^{2}$ Potsdam Institut für Klimafolgenforschung (PIK), Postfach 6012 03, D-14412 Potsdam, Germany, \\ ${ }^{3}$ Max-Planck-Institute für Meteorologie, Bundesstr. 55, D-20146 Hamburg, Germany \\ *The following participated in the Potsdam NPP Model Intercomparison: A. Bondeau (previous name: A. Fischer), \\ G. Churkina, W. Cramer, G. Colinet, J. Collatz, G. Dedieu, W. Emanuel, G. Esser, C. Field, L. François, A. Friend, \\ A. Haxeltine, M. Heimann, J. Hoffstadt, J. Kaduk, L. Kergoat, D. W. Kicklighter, W. Knorr, G. Kohlmaier, B. Lurin, \\ P. Maisongrande, P. Martin, R. McKeown, B. Meeson, B. Moore III, R. Nemani, B. Nemry, R. Olson, R. Otto, \\ W. Parton, M. Plöchl, S. Prince, J. Randerson, I. Rasool, B. Rizzo, A. Ruimy, S. Running, D. Sahagian, B. Saugier, \\ A. L. Schloss, J. Scurlock, W. Steffen, P. Warnant, and U. Wittenberg. \\ $\ddagger$ Previous name: A. Fischer.
}

\begin{abstract}
Eight terrestrial biospheric models (TBMs) calculating the monthly distributions of both net primary productivity (NPP) and soil heterotrophic respiration $\left(R_{H}\right)$ in the Potsdam NPP Model Intercomparison workshop are used to simulate seasonal patterns of atmospheric $\mathrm{CO}_{2}$ concentration. For each model, we used net ecosystem productivity $\left(\mathrm{NEP}=\mathrm{NPP}-\mathrm{R}_{\mathrm{H}}\right)$ as the source function in the TM2 atmospheric transport model from the Max-Planck Institute for Meteorology. Comparing the simulated concentration fields with detrended measurements from 25 monitoring stations spread over the world, we found that the decreasing seasonal amplitude from north to south is rather well reproduced by all the models, though the amplitudes are slightly too low in the north. The agreement between the simulated and observed seasonality is good in the northern hemisphere, but poor in the southern hemisphere, even when the ocean is accounted for. Based on a Fourier analysis of the calculated zonal atmospheric signals, tropical NEP plays a key role in the seasonal cycle of the atmospheric $\mathrm{CO}_{2}$ in the whole southern hemisphere. The relatively poor match between measured and predicted atmospheric $\mathrm{CO}_{2}$ in this hemisphere suggests problems with all the models. The simulation of water relations, a dominant regulator of NEP in the tropics, is a leading candidate for the source of these problems.
\end{abstract}

Keywords: NPP, global change, carbon dioxide, biosphere, hydrology, modelling, validation

\section{Introduction}

Validating large-scale models of terrestrial net primary productivity (NPP) is difficult. Site-based measurements provide critical data, but do not effectively address key components of scaling problem. Specifically, they are rarely consistent with the simulation scales (e.g. $0.5^{\circ} \times 0.5^{\circ}$ for the Potsdam intercomparison), and they are never spatially comprehensive (Cramer et al. 1999).

Correspondence: Dr B. Nemry, fax: +32-4-254-75-73,

E-mail: bnemry@ulg.ac.be
Analyses based on the spatial distribution of the concentration of $\mathrm{CO}_{2}$ and other tracers in the global atmosphere can provide a complementary approach to site-based validation, but with some important caveats. First, methods based on the spatial distribution of $\mathrm{CO}_{2}$ concentration provide information on the net carbon exchange or the difference between NPP and heterotrophic respiration $\left(\mathrm{R}_{\mathrm{H}}\right)$. Thus, the validation of NPP estimated from this approach is never stronger than the confidence in the model of $\mathrm{R}_{\mathrm{H}}$. Second, the analysis 
depends on net exchanges from all sources, including ocean exchanges, fossil fuel combustion, and land use change. As a consequence, uncertainties in all these fluxes appear as uncertainties in NPP. Third, patterns in the global atmosphere do not constrain the distribution of surface sources and sinks at a very high spatial resolution. They tend to reveal patterns at the scale of entire continents of broad latitude zones (e.g. Enting 1987; Tans et al. 1990).

Even with these caveats, analyses of the carbon cycle based on patterns of atmospheric $\mathrm{CO}_{2}$ play a central role in our current understanding. They were critical in demonstrating the link between the seasonality of NDVI and the seasonality of atmospheric $\mathrm{CO}_{2}$ (Fung et al. 1987; Heimann \& Keeling 1989; Knorr \& Heimann 1995) and the existence of a northern temperate terrestrial sink (Tans et al. 1990; Ciais et al. 1995; Randerson et al. 1997). Some of these analyses solved for the spatial distribution of surface sources and sinks for carbon with formal inversions. Others ran in forward mode, simulating the expected atmospheric patterns based on simulated fluxes and atmospheric transport.

As a contribution to the Potsdam NPP Model Intercomparison, we conducted experiments with eight terrestrial models, using the TM2 tracer transport model to transform surface fluxes into concentration fields. The overall approach was similar to that used by Heimann et al. (1998), though we used a different suite of terrestrial models and added a Fourier analysis to strengthen the interpretation of seasonality and the relative contributions of individual source regions to the concentration patterns in various parts of the atmosphere.

\section{Description of the TBMs}

For this study, we analysed eight of the TBMs participating in the Potsdam NPP model Intercomparison workshop (Table 1). All of these models, as well as several of the others not analysed here calculate both NPP and $\mathrm{R}_{\mathrm{H}}$, allowing studies based on NEP.

SDBM holds a special position among these eight TBMs since it uses the satellite-derived normalized-differencevegetation index (NDVI, from Gallo 1992) to calculate the photosynthetically active radiation absorbed by the canopy. Knorr \& Heimann (1995) calibrated SDBM in two steps. First, they determined two global parameters, the light-use efficiency in NPP and the temperature sensitivity of $\mathrm{R}_{\mathrm{H}}$ to match the seasonal atmospheric $\mathrm{CO}_{2}$ signal at five northern monitoring stations. The annual integral of $\mathrm{R}_{\mathrm{H}}$ is constrained to be equal everywhere to the local annual NPP. Second, they analysed the seasonal $\mathrm{CO}_{2}$ concentration simulated at a tropical station (Ascension Island, $7.9^{\circ} \mathrm{S}$ ) and a southern station (Cape Grim, 40.7 $\mathrm{S}$ ), where water stress has a large influence on the seasonal atmospheric $\mathrm{CO}_{2}$. They also compared their annual tropical NPP with an estimate based on the vegetation map by Matthews (1983). They concluded that both NPP and $\mathrm{R}_{\mathrm{H}}$ undergo the impact of drought stress, despite uncertainties linked to nonbiospheric sources in the tropics and to evapotranspiration, estimated independently of vegetation.

The other TBMs analysed here are prognostic models (Ruimy et al. 1999) that calculate the vegetation phenology from climatic conditions instead of prescribing it from the satellite observations of surface reflectance. A complete description of the NPP models is in Cramer et al. (1999)

Table 1 General characteristics of eight Terrestrial Biosphere Models (TBMs) supplying Net Primary Productivity (NPP) and Heterotrophic Respiration $\left(\mathrm{R}_{\mathrm{H}}\right)$ (for model references, cf. Cramer et al. 1999)

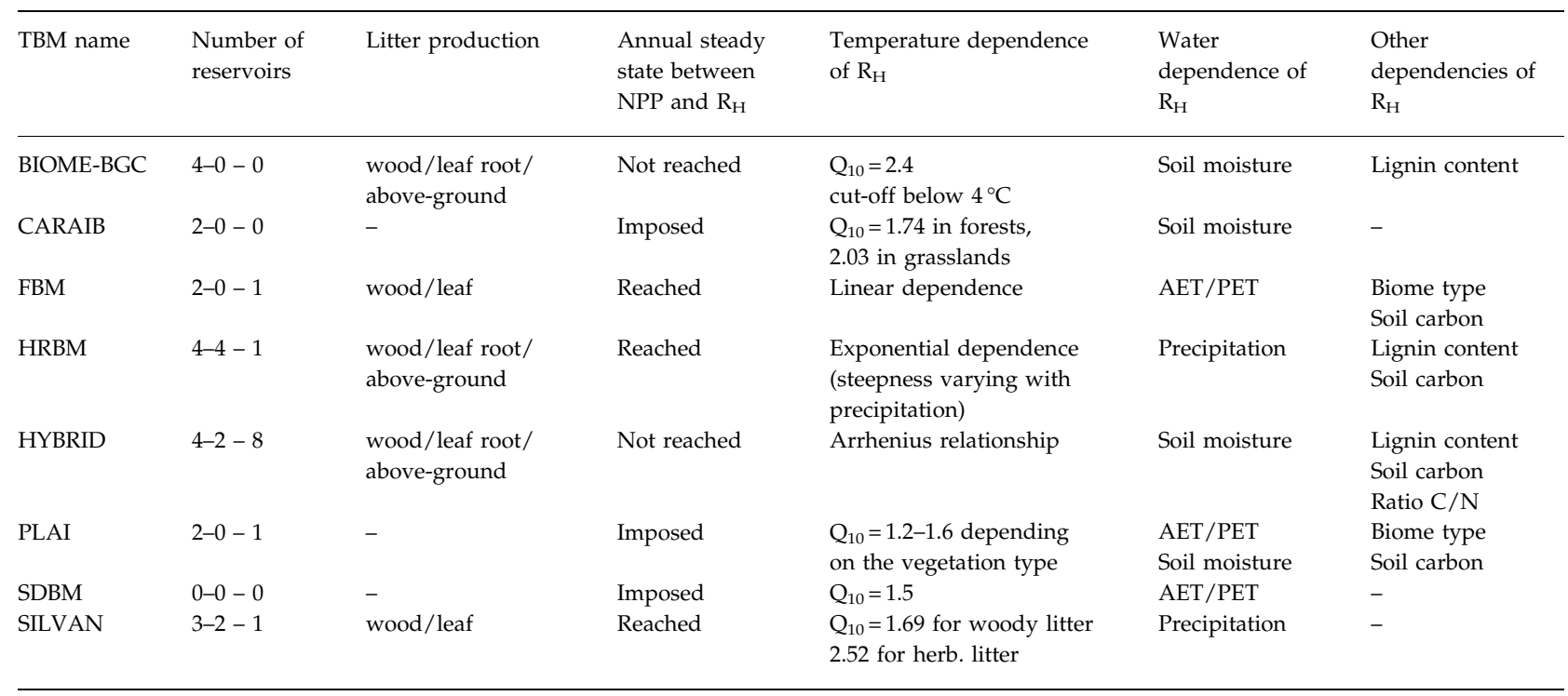


and references therein. The following subsections add a general description of the various ways followed by the TBMs to model litter production and $R_{H}$ flux. These carbon fluxes increase and decrease soil carbon content, respectively.

\section{Litter production}

CARAIB and SDBM do not calculate litter production explicitly. Soil carbon is simply determined so that annual integrals of NPP and $R_{H}$ are equal in each grid cell. The other prognostic models distinguish leafy and woody litter. Only BIOME-BGC, HRBM and HYBRID distinguish between root and above-ground litter. BIOME-BGC simulates the seasonal litter production as a fraction of the carbon produced during a year.

HRBM starts litter production in tundra, cool and cold mixed biomes, temperate and cold deciduous biomes only when the monthly temperature drops to the half of the mean temperature of the warmest month. The herbaceous phytomass is then reduced by half every 14 days during the following 3 months. The litter production in the other biomes is derived from the mean stand age of the plant material. The woody litter production is constant during the year. Herbaceous litter production is distributed among months to be consistent with changes in AET. HYBRID produces litter annually for the evergreen and deciduous forests but on a daily basis for grasslands.

FBM uses a linear relationship between litter production and the sizes of the biomass pools in evergreen forests. It includes a leaf abscission phase for grasslands and deciduous forests. PLAI simulates litter production with a rate coefficient that is constant throughout the year for evergreen forests. Litter is produced only in the fall in grasslands and deciduous forests. In SILVAN, a constant fraction of woody material is transferred to the litter throughout the year. A small, constant fraction of leaf biomass in deciduous forests is used for litter production
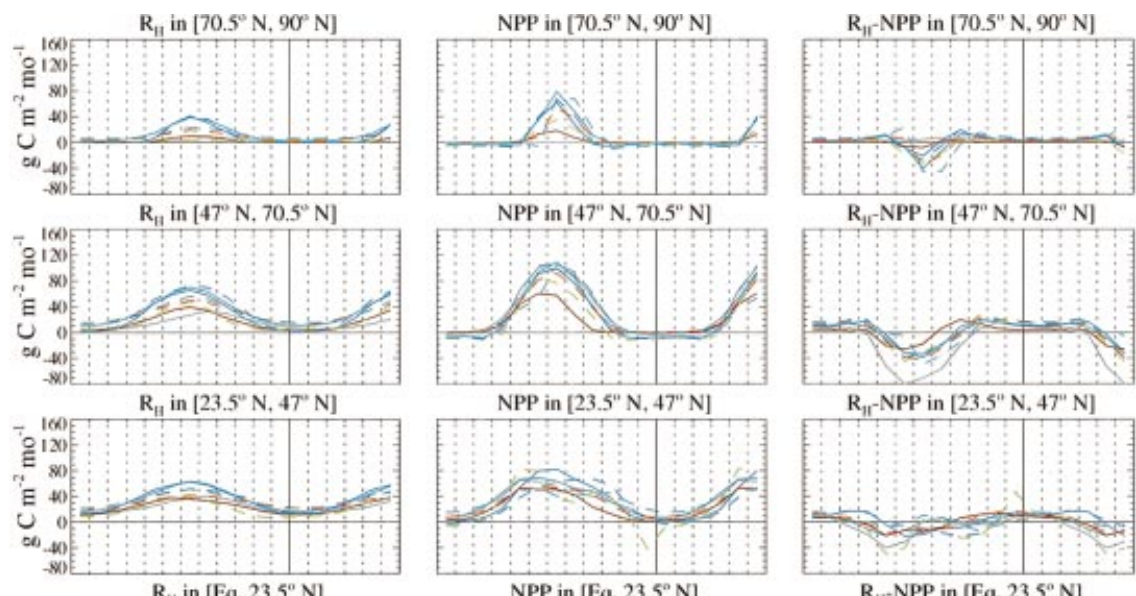

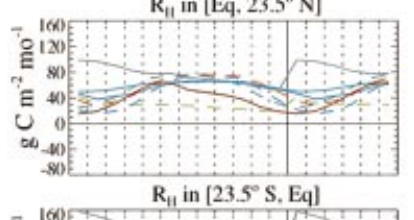

$\mathrm{NPP}$ in $\left[\mathrm{Eq} .23 .5^{\circ} \mathrm{N}\right]$

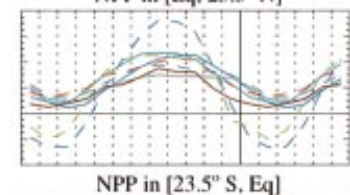

$\mathrm{NPP}$ in $\left[23.5^{\circ} \mathrm{S}, \mathrm{Eq}\right]$
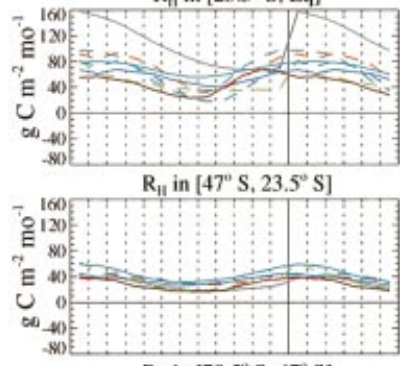

$\mathbf{R}_{\mathrm{H}}$ in $\left[70.5^{\circ} \mathrm{S}, 47^{\circ} \mathrm{S}\right]$

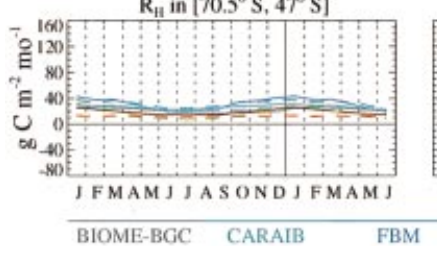

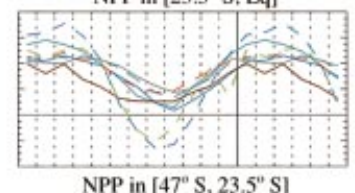

$\mathrm{NPP}$ in $\left[47^{\circ} \mathrm{S}, 23.5^{\circ} \mathrm{S}\right]$

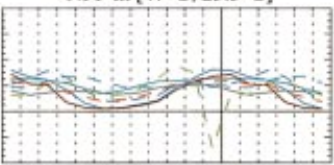

$\mathrm{NPP}$ in $\left[70.5^{\circ} \mathrm{S}, 47^{\circ} \mathrm{S}\right]$

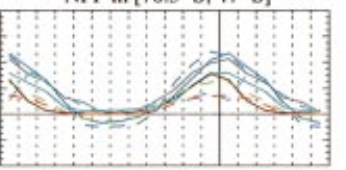

J FMAM J JASOND J FMAM J

HRBM

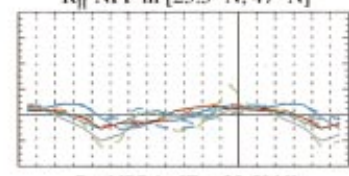

$\mathrm{R}_{11} \mathrm{NPP}$ in [Eq. 23.5 $\left.\mathrm{N}\right]$

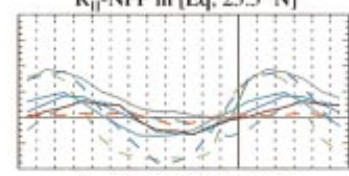

$\mathrm{R}_{11^{-}} \mathrm{NPP}$ in $\left[23.5^{\circ} \mathrm{S}, \mathrm{Eq}\right]$

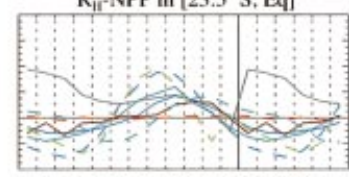

$R_{11}-\mathrm{NPP}$ in $\left[47^{\circ} \mathrm{S}, 23.5^{\circ} \mathrm{S}\right]$

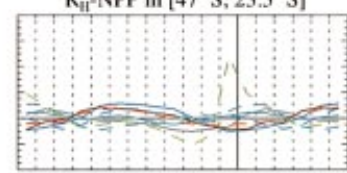

$R_{\mathrm{H}^{-}} \mathrm{NPP}$ in $\left[70.5^{\circ} \mathrm{S}, 47^{\circ} \mathrm{S}\right]$

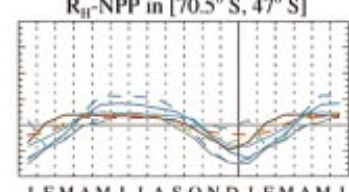

J FMAM J JASONDJFMAM J

PLAI $--\overline{S D B M}^{-}-\overline{\text { SILVAN }}{ }^{-}$ tivity. 
between leaf flush in the spring and shedding in the fall. Leaf shedding is triggered when the daily minimum temperature drops below $3^{\circ} \mathrm{C}$ for temperate deciduous forests, $0^{\circ} \mathrm{C}$ for other deciduous forests, and $-3^{\circ} \mathrm{C}$ for tundra. Nearly all of the herbaceous biomass is shed within a month. Leaf fall is triggered for grasslands and tropical deciduous ecosystems when the ratio of actual to potential evapotranspiration drops below 0.4 . All herbaceous biomass is shed within 15 days provided drought persists.

\section{Heterotrophic respiration}

Most of the $\mathrm{R}_{\mathrm{H}}$ models are somewhat preliminary. In all of the TBMs except FBM, the increase in $\mathrm{R}_{\mathrm{H}}$ with temperature is exponential; in FBM, it is linear. $Q_{10}$ values range from 1.2 to 1.6 in PLAI to 2.52 in the herbaceous litter of SILVAN. With HRBM, the relationship is a function of precipitation, reaching a maximum at $150 \mathrm{~mm} \mathrm{month}^{-1}$. SILVAN also uses precipitation to account for the water influence on $\mathrm{R}_{\mathrm{H}}$. FBM and SDBM use the ratio of actual to potential evapotranspiration, and the other TBMs (BIOME-BGC, CARAIB, HYBRID and PLAI) calculate soil moisture. FBM, HRBM, HYBRID and PLAI consider the soil as a pool where carbon is calculated explicitly. CARAIB, PLAI and SDBM assume annual equilibrium between NPP and $\mathrm{R}_{\mathrm{H}}$ at all locations. The other models do not.

\section{Zonal analysis of TBM outputs}

\section{Seasonal cycle of the biospheric fluxes}

Figure 1 summarizes the seasonality of NPP, $\mathrm{R}_{\mathrm{H}}$ and $\mathrm{R}_{\mathrm{H}}-$ NPP ( $\mathrm{g} \mathrm{C} \mathrm{m}^{-2}$ month $^{-1}$ ) calculated by the various TBMs. The zonal averages of these fluxes are presented in the tropical bands $\left[23.5^{\circ} \mathrm{S}, 0^{\circ}\right]$ and $\left[0^{\circ}, 23.5^{\circ} \mathrm{N}\right]$, two inner temperate bands $\left[47^{\circ} \mathrm{S}, 23.5^{\circ} \mathrm{S}\right]$ and $\left[23.5^{\circ} \mathrm{N}, 47^{\circ} \mathrm{N}\right]$, two outer temperate bands $\left[70.5^{\circ} \mathrm{S}, 47^{\circ} \mathrm{S}\right]$ and $\left[47^{\circ} \mathrm{N}, 70.5^{\circ} \mathrm{N}\right]$, and the arctic band $\left[70.5^{\circ} \mathrm{N}, 90^{\circ} \mathrm{N}\right]$. The desert of Antarctica $\left[90^{\circ} \mathrm{S}, 70.5^{\circ} \mathrm{S}\right]$ includes no significant biospheric fluxes. The width of these bands is three times the latitudinal extent of the transport grid cells $\left(7.826^{\circ}\right.$ except polar cells which are only half this large). The latitudes $23.5^{\circ} \mathrm{S}$ and $23.5^{\circ} \mathrm{N}$ are very close to the boundaries of the tropics, while the latitudes $70.5^{\circ} \mathrm{S}$ and $70.5^{\circ} \mathrm{N}$ are about $4^{\circ}$ poleward from the Arctic and Antarctic Circles $(\approx 450 \mathrm{~km})$.

FBM, HYBRID and PLAI simulate negative NPP during winter in the temperate latitudes. This indicates that autotrophic respiration is larger than photosynthetic assimilation, which should be very small if not zero during this period. Furthermore, HYBRID and PLAI also produce clearly negative NPP values during the dry seasons in the tropics. The bimodal oscillation in the NPP signal from HYBRID in the mid-temperate latitudes is due to the calculation of tree growth at the end of the year.

The seasonality of the $R_{H}$ signal is particularly small in the south temperate and arctic bands. In those bands, NPP has a greater amplitude. Elsewhere, the seasonal amplitude is generally lower for $\mathrm{R}_{\mathrm{H}}$ than for NPP but not negligible. An exception is the simulation by BIOME-BGC for the tropics, where $\mathrm{R}_{\mathrm{H}}$ is more seasonal than NPP.

The discrepancy among simulations from the eight models is generally lower for $R_{H}$ than for NPP, except in the tropics. The minimum values of both NPP and $R_{H}$ from all models tend to a common value close to zero in the extratropical bands because of the temperature influence. The minima are more dissimilar in the tropics, where soil water is expected to play a key role (Bondeau et al. 1999).

\section{Seasonal cycle of the biospheric emissions}

The seasonal signature of the terrestrial biosphere in atmospheric $\mathrm{CO}_{2}$ is influenced by the latitudinal distribution of the continental area. Depending on the TBM grid, land area covers $24.5-33.7 \times 10^{6} \mathrm{~km}^{2}$ in each temperate band of the northern hemisphere, $21.7-26.2 \times 10^{6} \mathrm{~km}^{2}$ in each tropical band, and $9.2-11.4 \times 10^{6} \mathrm{~km}^{2}$ in the inner south temperate band. Land area is much smaller in the arctic $\left(3.8 \times 10^{6} \mathrm{~km}^{2}\right)$ and outer south temperate zones $\left(0.5 \times 10^{6} \mathrm{~km}^{2}\right)$. Among the five dominant zones, the contrast in area reduces the seasonal influence of the inner south temperate zone. Moreover, the seasonality of the fluxes themselves in these latitudes is low due to the effectiveness of thermal inertia of the ocean in preventing the soil from freezing and mitigating the seasonal amplitude of continental temperatures. As a consequence, the simulated seasonality in atmospheric $\mathrm{CO}_{2}$ is mainly influenced by the four zones located between the Tropic of Capricorn and $70^{\circ} \mathrm{N}$.

\section{Annual values, seasonal amplitudes and phases}

Figure 2 presents latitudinal profiles for the annual integrals and the seasonal amplitudes of the modelled biospheric fluxes.

Each TBM produces a latitudinal profile of the annual $R_{H}$ which is nearly identical to the annual NPP profile. This is a consequence of the steady-state assumption. BIOME-BGC, which does not make a steady-state assumption, simulates a sink of $11 \mathrm{Pg} \mathrm{C}$ year $^{-1}$ in the north temperate zones, a source of $18 \mathrm{Pg} \mathrm{C}_{\text {year }}^{-1}$ from the intertropical band, and a sink of about $0.8 \mathrm{Pg} \mathrm{C}_{\mathrm{Cear}}{ }^{-1}$ in the south temperate bands. These sources and sinks are clear in the latitudinal profile of $\mathrm{R}_{\mathrm{H}}-\mathrm{NPP}$ (Fig. 2). The annual carbon exchange between the atmosphere and the 
biosphere from HYBRID is also not at steady state, but to a much lesser extent (source of around $0.9 \mathrm{Pg} \mathrm{C}_{\text {year }}{ }^{-1}$ ).

Most of the TBMs predict that the seasonal amplitude of NPP varies dramatically with latitude, while the pattern in $\mathrm{R}_{\mathrm{H}}$ is more muted. CARAIB and FBM simulate little seasonal $\mathrm{R}_{\mathrm{H}}$ amplitude south of $40^{\circ} \mathrm{N}$. BIOME-BGC and HYBRID simulate maximum seasonal amplitude of $\mathrm{R}_{\mathrm{H}}$ at the equator. The remaining models (HRBM, PLAI, SDBM and SILVAN) produce latitudinal distributions of seasonal amplitude close to each other and similar to the seasonal profiles of NPP.

The generally larger seasonal amplitude of NPP than $\mathrm{R}_{\mathrm{H}}$ implies that seasonal variation in NPP tends to drive seasonality in the net flux. The pattern is different in BIOME-BGC, where seasonality in $\mathrm{R}_{\mathrm{H}}$ dominates around the equator and seasonality in NPP drives seasonality in the net fluxes in the outer north temperate zone. In SDBM, the NPP and $\mathrm{R}_{\mathrm{H}}$ fluxes calculated by SDBM oscillate at comparable amplitudes south of $30^{\circ} \mathrm{N}$ and their difference has only a weak seasonal amplitude especially in the southern tropical zone.

All of the TBMs agree relatively well on the phasing of NPP and $R_{H}$ in the north temperate zones (Fig. 1). All the models simulate their maximum NPP in June or July and maximum $R_{H}$ in July or August. Minimum $R_{H}$ in these latitudes is in January except for HYBRID (1 to 2 months earlier), BIOME-BGC, and SDBM (both 1 month later). The month of minimum NPP in these temperate regions falls between October (FBM and HYBRID) and January (SDBM and HRBM).

In the tropics, the maximum NPP from all models lags the maximum precipitation, which occurs in August and January in the northern and southern tropical bands, respectively. Similarly, the minimum NPP from all the models lags the minimum precipitation, which occurs around 6 months after the humid season. Phase differences among TBMs can reach 4 months in these regions. In general, $\mathrm{R}_{\mathrm{H}}$ lags precipitation less than does NPP, and this dephasing results in large values of NEP.

\section{Other seasonal sources of atmospheric $\mathrm{CO}_{2}$}

To estimate the ocean contribution to the seasonal atmospheric signal, we add the fluxes calculated by Six \& Maier-Reimer (1996) with the Hamburg Model of the Ocean Carbon Cycle (HAMOCC3). The seasonal amplitude of ocean $\mathrm{CO}_{2}$ fluxes ranges from $\approx 15 \mathrm{~g} \mathrm{C} \mathrm{m}^{-2} \mathrm{month}^{-1}$ in the equatorial region to 70 and $120 \mathrm{~g} \mathrm{C} \mathrm{m}^{-2} \mathrm{month}^{-1}$ in the northern and southern temperate zones, respectively. These values are comparable to the seasonal amplitude of the terrestrial biospheric fluxes (Fig. 1). Nevertheless, the seasonal amplitude of the ocean $\mathrm{CO}_{2}$ emissions, the product of the ocean fluxes and areas in each band, does not exceed $0.15 \mathrm{PgCmonth}{ }^{-1}$ while the terrestrial bio- spheric emissions exceed $1 \mathrm{PgC}$ month $^{-1}$ northward of the Tropic of Capricorn. This proportion limits the potential influence of the ocean on the atmospheric $\mathrm{CO}_{2}$ signals to the southern extratropical latitudes.

The seasonality of the $\mathrm{CO}_{2}$ emissions from fossil fuel burning is low, but even if the industrial activity is assumed to be constant during the year, it introduces a seasonal signature in atmospheric $\mathrm{CO}_{2}$, through effect of seasonal wind patterns (Knorr \& Heimann 1995). We add the annual industrial emissions of 1990 supplied by Andres et al. (1996) at a spatial resolution of $1^{\circ} \times 1^{\circ}$.

Other sources like land use or tropical fires are poorly known (Crutzen et al. 1989). The present analysis does not explicitly include tropical fires in the seasonal sources, but we discuss their influence. Land use is implicitly considered in SDBM, since it is based on NDVI, but not in the other TBMs. This could be a source of uncertainty, though versions of HRBM with potential vegetation and agricultural regions produce similar results.

\section{Atmospheric transport: description and methodology}

\section{Atmospheric transport modelling}

The monthly net carbon fluxes $\mathrm{R}_{\mathrm{H}}$ - NPP supplied by the TBMs can be used as boundary conditions in a transport model. The fluxes are preliminarily converted from the Potsdam resolution $0.5^{\circ} \times 0.5^{\circ}$ to the transport model resolution. This averaging is a spatial smoothing that reduces the seasonal amplitude of the exchange fluxes.

The TM2 atmospheric transport model (Heimann \& Keeling 1989) simulates the three-dimensional distribution of any tracer through time, given fluxes of the tracer at the Earth surface. The model uses meteorology from 4dimensional data assimilation, meaning that the transport reflects observed weather. TM2 inputs are fields of wind, temperature, geopotential, and humidity from the European Centre for Medium-Range Weather Forecasts (ECMWF) with a spatial resolution of $2.5^{\circ} \times 2.5^{\circ}$ and a time step of 6 or $12 \mathrm{~h}$. These are used for preliminary calculations of horizontal air mass transport at a resolution of $10^{\circ} \times 7.826^{\circ}$ in longitude and latitude and to deduce the subgrid vertical air motions due to diffusion and cloud convection. The transport simulations were run with a time step of $4 \mathrm{~h}$. We used meteorological fields updated every 12h for 1987.

TM2 participated with 11 other atmospheric transport models in the Transport Comparison Project (TransCom) (Law et al. 1996). In this comparison, TM2 reproduced a realistic latitudinal distribution of the seasonal amplitudes of atmospheric $\mathrm{CO}_{2}$, performing at least as well as the GISS model from which it originates (Russell \& Lerner 1981). 

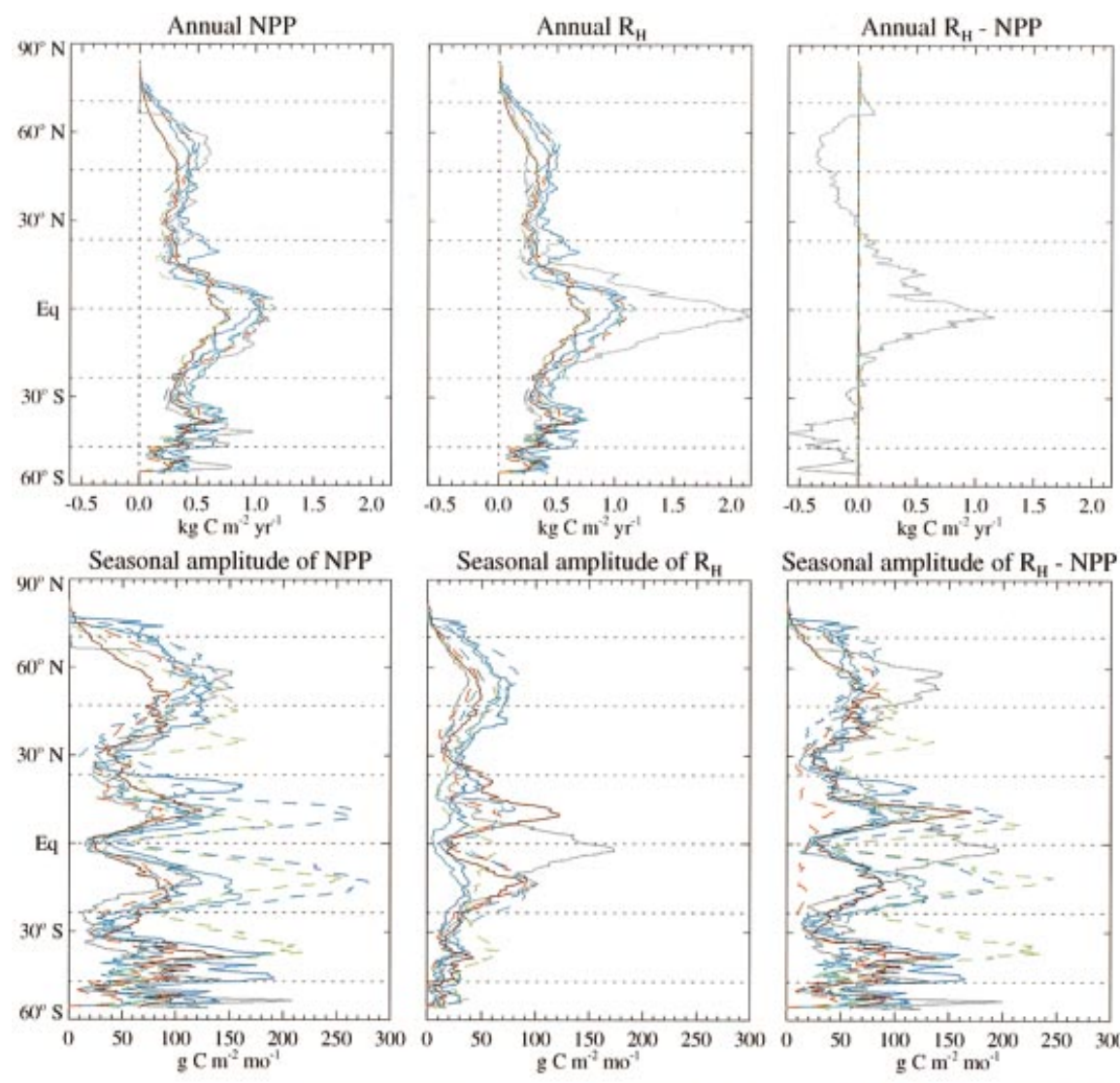

Seasonal amplitude of $R_{H}$
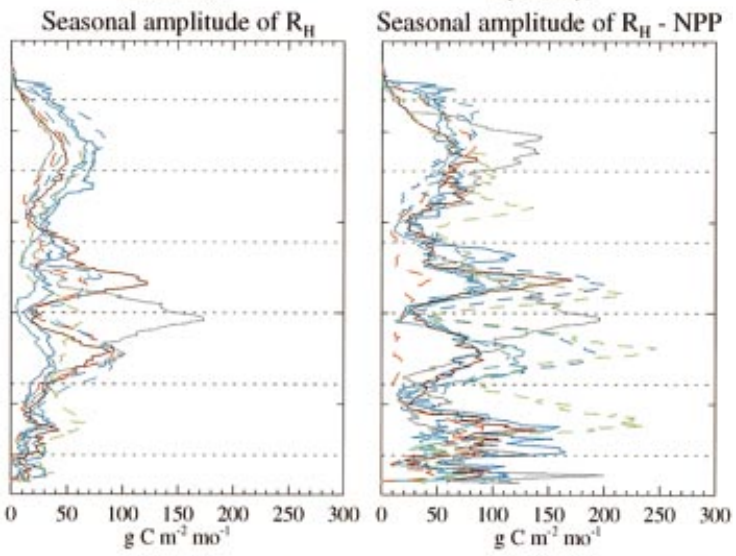

Fig. 2 Annual values and seasonal amplitudes of the biospheric fluxes from eight Terrestrial Biosphere Models. BIOME-BGC CARAIB FBM HRBM HYBRID PLAI SDBM SILVAN $\mathrm{R}_{\mathrm{H}}$ : heterotrophic respiration; NPP: net primary productivity.

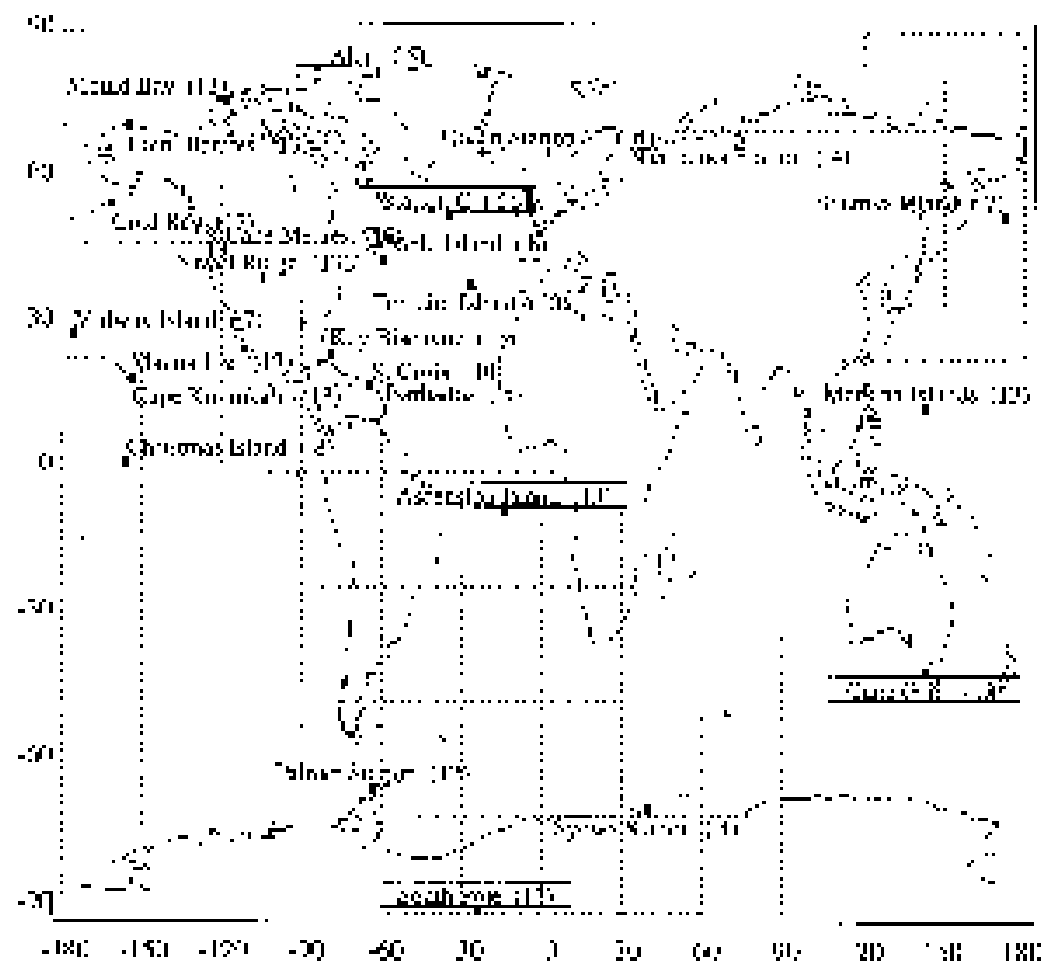

Fig. 3 Monitoring stations where $\mathrm{CO}_{2}$ is measured (Conway et al. 1994). The number of years between 1980 and 1992 containing 12-monthly $\mathrm{CO}_{2}$ values is given in brackets. One particular station is indicated in each latitudinal band (see text). 
Fig. 4 Zonal continental averages of simulated seasonal biospheric emissions $\left(\mathrm{Pg} \mathrm{C}\right.$ month $\left.^{-1}\right)$ simulated by eight Terrestrial Biosphere Models (TBMs), and corresponding seasonal atmospheric $\mathrm{CO}_{2}$ signals (ppmv) simulated near monitoring stations. The simulated atmospheric signals result from the TM2 transport model (Heimann \& Keeling 1989) coupled to a TBM, simulated $\mathrm{CO}_{2}$ emissions from ocean (Six \& Maier-Reimer 1996) and fossil fuel burning (Andres et al. 1996). The $\mathrm{CO}_{2}$ measurements (Conway et al. 1994) have been detrended and the observed interannual variability is indicated by error bars.
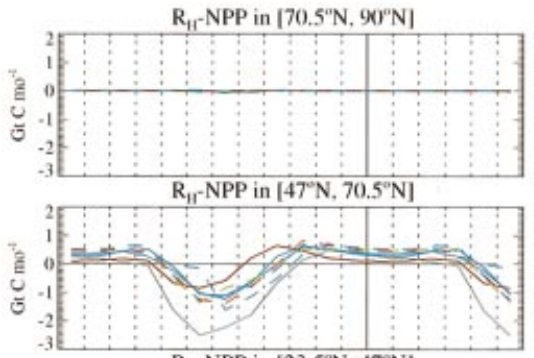

$\mathrm{R}_{11^{-}} \mathrm{NPP}$ in $\left[23.5^{\circ} \mathrm{N}, 47^{\circ} \mathrm{N}\right]$

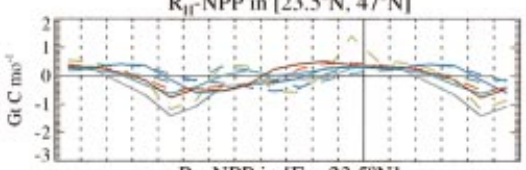

$\mathrm{R}_{11} \mathrm{NPP}$ in [Eq. $\left.23.5^{\circ} \mathrm{N}\right]$

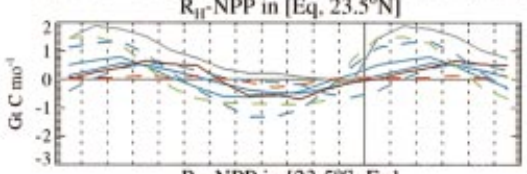

$\mathrm{R}_{\mathrm{Hr}} \mathrm{NPP}$ in $\left[23.5^{\circ} \mathrm{S}, \mathrm{Eq}\right]$
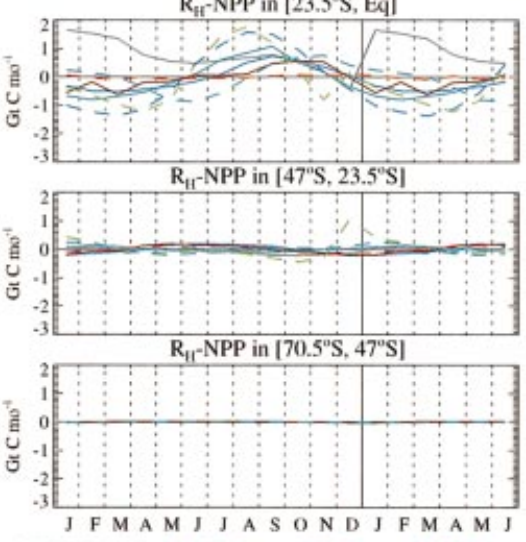

BIOME-BGC CARAIB FBM HRBM

HYBRID_ PLAI - SDBM - SILVAN

$\Phi$ Detrended measurements
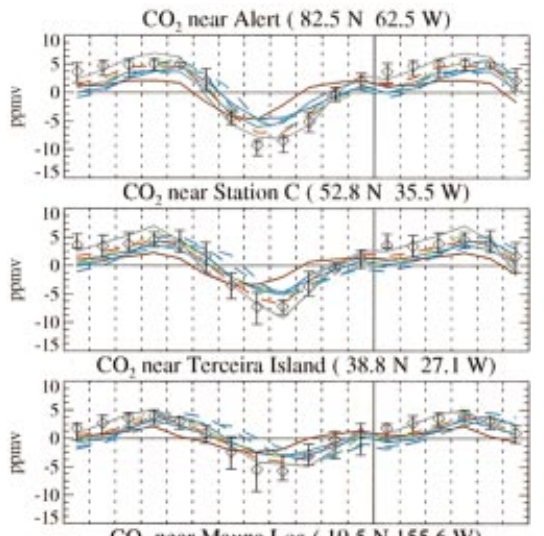

$\mathrm{CO}_{2}$ near Mauna Loa ( $\left.19.5 \mathrm{~N} 155.6 \mathrm{~W}\right)$
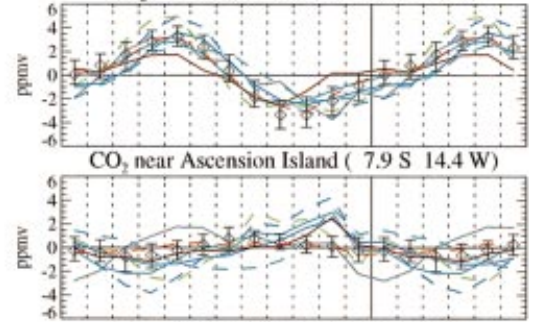

$\mathrm{CO}_{2}$ near Cape Grim $(40.7 \mathrm{~S} 144.7 \mathrm{E})$

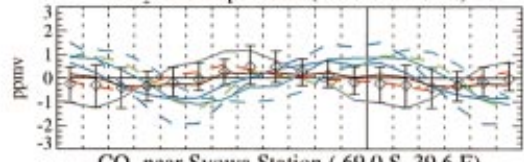

$\mathrm{CO}$, near Syowa Station ( $69.0 \mathrm{~S} 39.6 \mathrm{E})$

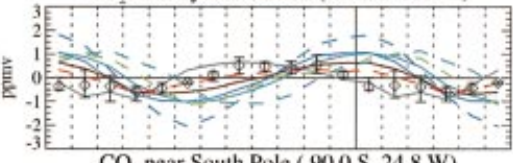

$\mathrm{CO}$, near South Pole ( 90.0 S $24.8 \mathrm{~W}$ )

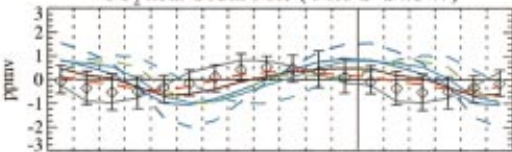

\section{Detrending the measured $\mathrm{CO}_{2}$ concentrations}

Several monitoring stations have supplied measured atmospheric $\mathrm{CO}_{2}$ for several years (Conway et al. 1994). Figure 3 maps the 25 monitoring stations considered in the present analysis. Each of these stations fulfils two criteria. First, at least 3 years between 1980 and 1992 include each 12-monthly measurements. If this first condition is satisfied, the long-term trend of the station record is estimated with a parabolic fit and removed from the data. Each seasonal cycle in the sequence resulting from this long-term subtraction is then correlated with its fundamental Fourier mode. As a second criterion, the interannual average $r^{2}$ of the resulting annual correlation coefficients must be larger than 0.8. If this second condition is satisfied, the station is selected and the annual average of each seasonal cycle in the detrended sequence is constrained to zero.

Application of these criteria allows us to reject stations where the interannual variability is not well known or where episodic $\mathrm{CO}_{2}$ sources have too much importance. For example, tropical fires appear during only a few months in the year and generate an atmospheric $\mathrm{CO}_{2}$ signal of about 1 ppmv, including high harmonics in addition to the fundamental mode. This contribution is perceptible at Ascension Island but not dominating.

\section{Detrending of the simulated $\mathrm{CO}_{2}$ signals}

All transport simulations have been run during four years. The results have been detrended as follows. We estimate the trend of the simulations from the best linear fit of the monthly results in the third and fourth years. The fourth seasonal cycle is detrended by the removal of this linear fit. After this subtraction, we further remove the annual average, leaving the seasonal cycle with a zero mean and no trend. This processing is particularly important with BIOME-BGC and HYBRID, which are not in steady state. 
Analysis of the biospheric signature in the atmospheric $\mathrm{CO}_{2}$ signal

Due to transport, the time series of $\mathrm{CO}_{2}$ concentrations at any point in the atmosphere is influenced by fluxes from a number of regions. To isolate the role of various geographical regions, we performed simulations with seasonal carbon fluxes limited to selected regions of the terrestrial biosphere. The Fourier analysis of results from these geographically restricted simulations allows us to estimate the relative influence of each region on the $\mathrm{CO}_{2}$ signal at all others (François et al. 1996; Nemry et al. 1996). For this analysis, we divide the globe into eight zones with southern limits at latitudes $90^{\circ} \mathrm{S}, 70.5^{\circ} \mathrm{S}, 47^{\circ} \mathrm{S}, 23.5^{\circ} \mathrm{S}$, $0^{\circ}, 23.5^{\circ} \mathrm{N}, 47^{\circ} \mathrm{N}$ and $70.5^{\circ} \mathrm{N}$. Each of these bands contains three latitudinal bands of the TM2 grid. They define eight tropospheric zones and cover the seven biospheric zones (termed ' $a$ ' and ' $b$ ' defined in the section 'Seasonal cycle of the biospheric fluxes'). The entire land biosphere is labelled zone ' $\mathrm{B}$ '. With each TBM, eight 4-year transport simulations were run, limiting terrestrial biospheric fluxes to one on the eight biospheric zones for each simulation. TM2 provides a $\mathrm{CO}_{2}$ concentration in the tropospheric zones ' $\mathrm{a}$ ' every $4 \mathrm{~h}$. We combined these into monthly averages to produce a seasonal signal, which was then detrended as described in the section 'Detrending of the simulated $\mathrm{CO}_{2}$ signals'. Using a period $\mathrm{T}=1$ year to define the frequency $\omega=2 \pi / \mathrm{T}$, we calculated the fundamental Fourier amplitudes $C_{a, b}$ and $C_{a, b}$ and phases $\gamma_{a, b}$ and $\gamma_{a, b}$ of the detrended signals from the whole biosphere ' $\mathrm{B}$ ' and each biospheric zone ' $b$ '. The fundamental Fourier mode in any tropospheric zone ' $a$ ' from biospheric zone $\mathrm{z}={ }^{\prime} \mathrm{b}$ ' or ' $\mathrm{B}$ ' is

$$
\mathrm{S}_{\mathrm{a}, \mathrm{z}}(\mathrm{t})=\mathrm{C}_{\mathrm{a}, \mathrm{z}} \sin \xi_{\mathrm{a}, \mathrm{z}}(\mathrm{t})
$$

where $\xi_{a, z}(t)=\omega t+\gamma_{a, z}$. The Fourier modes of the partial signals can be written

$$
\mathrm{S}_{\mathrm{a}, \mathrm{b}}(\mathrm{t})=\mathrm{P}_{\mathrm{a}, \mathrm{b}} \sin \xi_{\mathrm{a}, \mathrm{B}}(\mathrm{t})+\mathrm{Q}_{\mathrm{a}, \mathrm{b}} \cos \xi_{\mathrm{a}, \mathrm{b}}(\mathrm{t})
$$

where $P_{a, b}$ and $Q_{a, b}$ are the amplitudes of fundamental Fourier modes of the partial signals, respectively, in phase and in quadrature with the fundamental Fourier modes of the total signal:

$$
\begin{aligned}
& \mathrm{P}_{\mathrm{a}, \mathrm{b}}=\mathrm{C}_{\mathrm{a}, \mathrm{b}} \cos \left(\gamma_{\mathrm{a}, \mathrm{b}}-\gamma_{\mathrm{a}, \mathrm{b}}\right) \\
& \mathrm{Q}_{\mathrm{a}, \mathrm{b}}=\mathrm{C}_{\mathrm{a}, \mathrm{b}} \sin \left(\gamma_{\mathrm{a}, \mathrm{b}}-\gamma_{\mathrm{a}, \mathrm{b}}\right)
\end{aligned}
$$

Because of the linearity of the atmospheric transport model, the sum of the seven amplitudes $\mathrm{P}_{\mathrm{a}, \mathrm{b}}$ in any zone
' $a$ ' is equal to $C_{a, B}$ while the sum of the seven amplitudes $Q_{a, b}$ is zero. The amplitude $P_{a, b}$ is negative if the fundamental modes of the partial and total signals $S_{a, b}(t)$ and $S_{a, b}(t)$ in the tropospheric zone ' $a$ ' are out of phase by more than 3 months.

\section{Results and discussion}

\section{Comparison with selected monitoring stations}

Figure 4 presents the zonal net carbon exchanges of the terrestrial biosphere $\left(\mathrm{Pg} \mathrm{C}\right.$ month $\left.^{-1}\right)$ obtained by multiplying the $\mathrm{R}_{\mathrm{H}^{-}}$NPP fluxes from Fig. 1 by the continental areas in each latitude zone. The monthly averages of atmospheric $\mathrm{CO}_{2}$ concentration simulated by TM2 are also presented for one monitoring station selected in each band, as indicated in Fig. 3. For each monitoring station, the interannual average of the detrended seasonal observations is used as a reference cycle and compared with the seasonal cycle of atmospheric $\mathrm{CO}_{2}$ simulated over the grid cell where the station is located. The interannual variability around each monthly value of the reference cycle is represented by the extremes found in the detrended series.

Atmospheric transport plays a key role in the seasonality of $\mathrm{CO}_{2}$ concentration in the arctic, outer south temperate and antarctic zones. Though the local sources of biospheric carbon are small in these zones, the seasonal amplitude of the atmospheric $\mathrm{CO}_{2}$ has the same magnitude as in the neighbouring zones. All the TBMs do a good job of reproducing the north to south gradient of seasonal amplitude of the atmospheric concentration. The peak to peak values decrease from about $15 \mathrm{ppmv}$ in the North to 1 ppmv in the South. Nevertheless, the simulated amplitudes are slightly too small at the northern stations. In particular, HRBM produces only about one half the observed amplitude.

At the four stations selected in the northern hemisphere (Alert, $82.5^{\circ} \mathrm{N}$; Station $\mathrm{C}, 52.8^{\circ} \mathrm{N}$; Terceira Island, $38.8^{\circ} \mathrm{N}$; Mauna Loa, $19.5^{\circ} \mathrm{N}$ ), the TBMs overestimate $\mathrm{CO}_{2}$ concentration in the summer trough.

The seasonal atmospheric $\mathrm{CO}_{2}$ signal at Ascension Island $\left(7.9^{\circ} \mathrm{S}\right)$ includes the influence of the African intertropical vegetation and the signal of tropical biomass burning (Knorr \& Heimann 1995). The observed amplitude is about 2 ppmv (peak to peak value) and is rather well reproduced by SDBM, and to a lesser extent by FBM and HRBM. The other TBMs overestimate the amplitude. The correction due to the biomass burning which is expected to produce a trough in April and a peak in August (Iacobellis etal. 1994) would increase the mismatch by a fraction of 1 ppmv.

The differences between the seasonal signals at Cape Grim $\left(40.7^{\circ} \mathrm{S}\right)$, Syowa Station $\left(69.0^{\circ} \mathrm{S}\right)$ and South Pole 
$\left(90.0^{\circ} \mathrm{S}\right)$ are much smaller in the observations than in the simulations. Only SDBM succeeds in predicting the correct amplitude and phase of the seasonal atmospheric $\mathrm{CO}_{2}$.

\section{Comparison with all monitoring stations}

Heimann et al. (1998) calculate for each TBM the annual average of the squared differences between the simulated and observed monthly $\mathrm{CO}_{2}$ concentrations. The squared difference at each month $(\mathrm{m})$ is weighted by the interannual variance $\sigma^{2}(\mathrm{~m})$ of the measurements. To evaluate the seasonal evolution of the dispersion between the TBMs at any station, we consider the sequence of the monthly variances $\mathrm{V}_{\text {tot }}(\mathrm{m})$ of the model results around the measurements at month $\mathrm{m}$. Weighted by the observed seasonal amplitude $\Delta C_{O B S}$, these variances are, at month $\mathrm{m}$,

$$
V_{\text {tot }}(m)=\frac{1}{8} \sum_{T B M=1}^{8}\left[\frac{C_{T B M}(m)-C_{O B S}(m)}{\Delta C_{O B S}}\right]^{2}
$$

where $\mathrm{C}_{T B M}(\mathrm{~m})$ and $\mathrm{C}_{O B S}(\mathrm{~m})$ are the simulated and observed detrended $\mathrm{CO}_{2}$ concentrations. The time series $\mathrm{V}_{\text {tot }}(\mathrm{m})$ fluctuate around annual values that increase approximately from 0.05 in the north to 0.4 in the south. Eqn 5 can be split into two terms:

$$
V_{\text {tot }}(m)=\left[\frac{\hat{C}(m)-C_{O B S}(m)}{\Delta C_{O B S}}\right]^{2}+V_{\bmod }(m)
$$

where $\hat{C}$ stands for the average of the results $C_{T B M}$ from the eight models, and

$$
V_{\text {mod }}(m)=\frac{1}{8} \sum_{T B M=1}^{8}\left[\frac{C_{T B M}(m)-\hat{C}(m)}{\Delta C_{O B S}}\right]^{2}
$$

Both terms in right-hand side of Eqn 6 have the same order of magnitude except in August or September for the stations located in the northern hemisphere. In these months, the first term clearly peaks to values that are at least four times higher than in the rest of the year, indicating that all the models fail in predicting the $\mathrm{CO}_{2}$ concentration measured in summer, when the biosphere is a $\mathrm{CO}_{2}$ sink. In the southern hemisphere, the values of $\mathrm{V}_{\text {tot }}(\mathrm{m})$ are maximum twice a year, around January and June. These peaks are due to the first term, except at Cape Grim, where the second term $V_{\text {mod }}(m)$ dominates all the year.

The fundamental Fourier modes (those with a period of one year) provide a compact way to summarize the seasonal dynamics at the 25 selected monitoring stations and to evaluate the influence of the ocean and the fossil fuel burning. Because the Fourier modes are calculated from the 12-monthly values, their amplitude and phase contain more information than the amplitude and timing determined from the two extremes in the original signal.

Figure 5 displays the amplitudes and the time of the seasonal minimum of the fundamental Fourier modes based on measured and simulated $\mathrm{CO}_{2}$ concentrations at the 25 selected stations of Fig. 3. The interannual variability of the measured values was obtained at each station from the Fourier analysis of the individual detrended seasonal cycles used to construct the reference seasonal cycle. The latitudinal profiles are calculated with the biospheric seasonality alone, then with the ocean influence included and finally with both the ocean and the fossil fuel burning contributions.

The seasonal amplitudes in the north are generally too low except with BIOME-BGC and SDBM (Fig. 5a). This is particularly true with HRBM as already noted in Fig. 4. The effect of the ocean and fossil fuel burning is weak.

The simulated phase in the northern hemisphere ranges from a lag of 2 months, mainly with PLAI and SILVAN in the northern temperate latitudes, to a lead of two months with HRBM in the extratropical northern regions (Fig. 5b). The phases of CARAIB and HYBRID in the northern hemisphere are generally close to the observations, but not as close as that of SDBM, which was calibrated to match the seasonality of the atmospheric $\mathrm{CO}_{2}$ signal.

In the tropics, the effect of the ocean and the fossil fuel burning on the month of the $\mathrm{CO}_{2}$ minimum varies among the TBMs. The effect of the ocean is generally larger than that of fossil fuel. Nevertheless, at Christmas Island $\left(3^{\circ} \mathrm{N}\right)$, the seasonality due to fossil fuel burning advances the $\mathrm{CO}_{2}$ minimum by about one month, improving the match with observations for all models except CARAIB and HYBRID. Predicted $\mathrm{CO}_{2}$ minima in the southern extratropical zones from the TBMs except BIOME-BGC and SDBM lag observations by 1-5 months. Adding the ocean and fossil fuel seasonality does not improve the match between the simulations and the observations in these regions.

\section{Location of the biospheric influences}

As explained in section 'Analysis of the biospheric signature in the atmospheric $\mathrm{CO}_{2}$ signal', the seasonal tropospheric signal in any zone ' $a$ ' is the sum of the partial seasonal signals from the biospheric regions located in the different zones ' $b$ '. Each of the partial signals may be split into two seasonal components, one in phase with the signal of the whole biosphere, and the other one out of phase. The amplitude $\mathrm{P}_{\mathrm{a}, \mathrm{b}}$ of the first component is displayed in Fig. 6. 

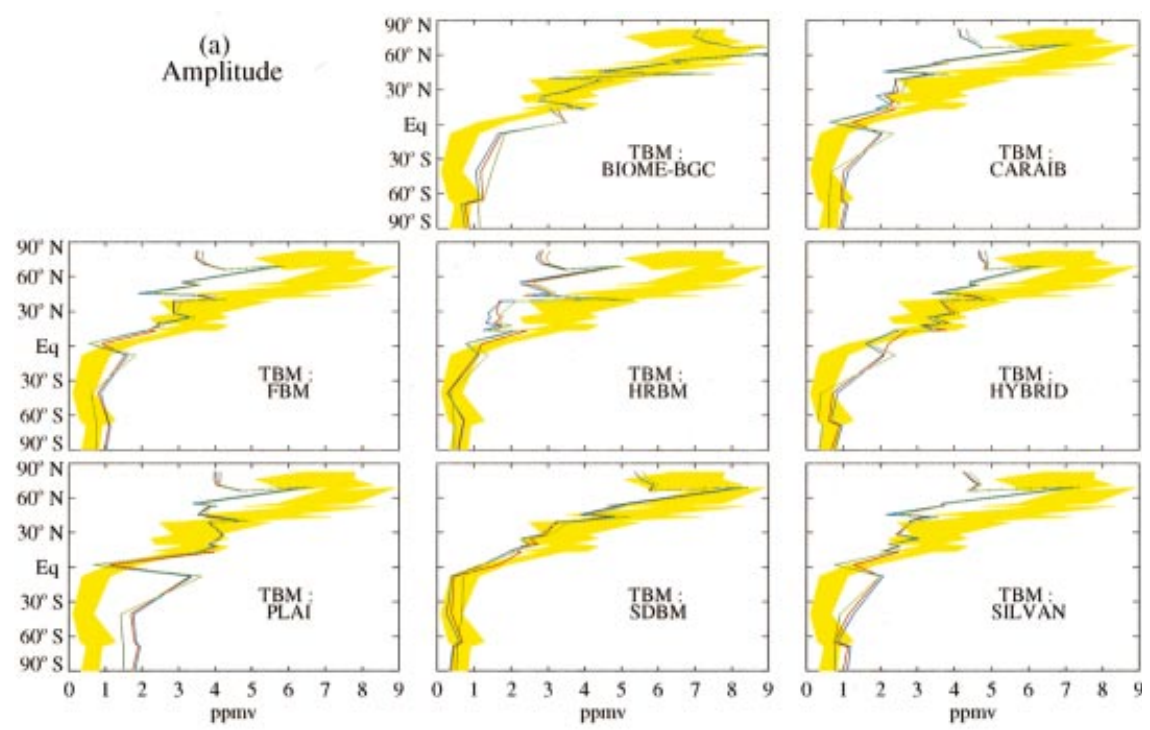

(b)

Occurrence of the minimum in the year
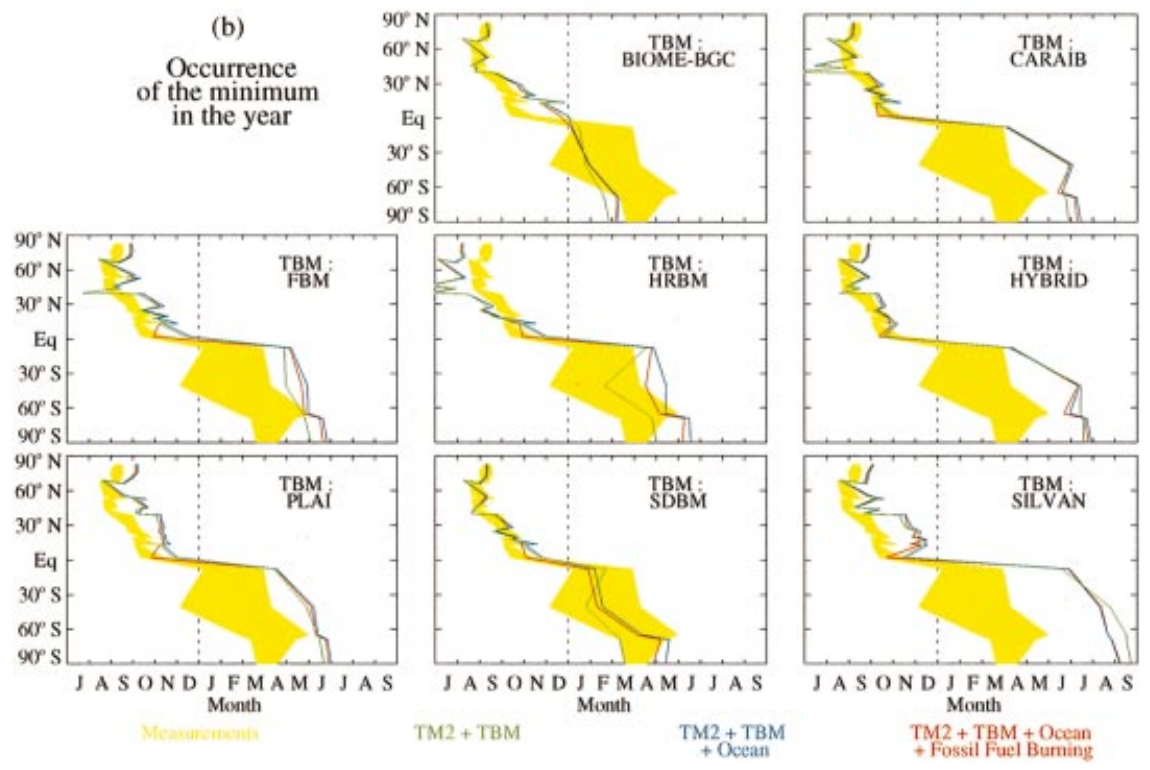

Fig. 5 Latitudinal distribution of (a) amplitude (b) phase of the fundamental Fourier modes (period of one year) from observed and simulated detrended seasonal atmospheric $\mathrm{CO}_{2}$ concentrations. Yellow: observation (Conway etal. 1994); Green: atmospheric transport model TM2 (Heimann et al. 1989) coupled to a Terrestrial Biospheric Model (TBM); Blue: TM2 coupled to a TBM and an ocean carbon model (Six \& Maier-Reimer 1996); Red: same as blue, with fossil fuel burning (Andres et al. 1996) included.

As expected, the biosphere from the zones north of $70.5^{\circ} \mathrm{N}$ and south of $47^{\circ} \mathrm{S}$ is virtually nonexistent from the point of view of the seasonal atmospheric $\mathrm{CO}_{2}$ signal simulated anywhere. The seasonal dynamics of atmospheric $\mathrm{CO}_{2}$ in the Arctic and the northern temperate zones is dominated by the biospheric fluxes in the northern temperate bands, mainly the outer one. The influence from the inner northern temperate band is nonetheless dominated by an opposite contribution from the northern tropical band in SILVAN. The negative influence of the northern tropical biosphere on the atmosphere in more northerly zones indicates a lag of 3-6 months with respect to the total simulated signal. The small positive contribution from the southern tropical fluxes to arctic and temperate concentrations corresponds to a dephasing smaller than 3 months (or higher than 9 months). In most locations, the contributions of the northern and southern tropical bands to the seasonal tropospheric signal have opposite signs for the simulations with all models except BIOME-BGC. SDBM predicts small contributions from these bands.

In the northern tropics, contributions to the seasonal $\mathrm{CO}_{2}$ dynamics are divided approximately equally between local influence and inputs from more northern zones for all models except SDBM, where local influences are very minor. The southern tropical vegetation generates a signal that is out of phase by 3-6 months from the phase of the total signal, except for BIOME-BGC.

In the southern tropics, the northern temperate biosphere has virtually no impact. The local vegetation is the main biospheric source of atmospheric seasonality. It produces a positive signal while the northern tropical biosphere has 

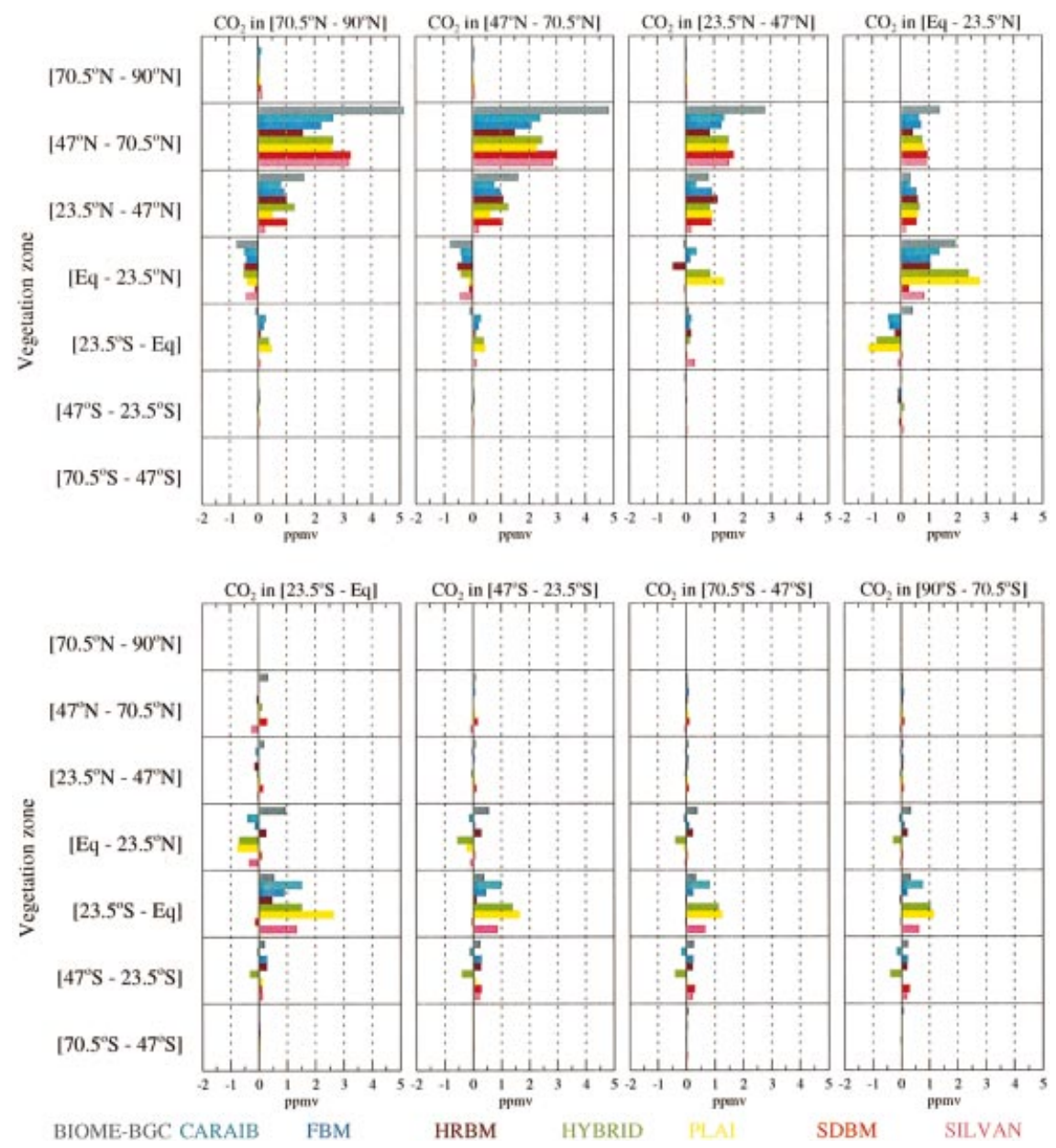

Fig. 6 Influence of the vegetation zones on the seasonal tropospheric $\mathrm{CO}_{2}$ concentration according to eight Terrestrial Biosphere Models. The fundamental Fourier modes have been calculated in each zone and their amplitudes projected onto the direction of the fundamental mode of the signal from the total biosphere.

a slightly negative influence except in the results of HRBM and BIOME-BGC. SDBM is also an exception since the signals from the five major vegetation zones between $47^{\circ} \mathrm{S}$ and $47^{\circ} \mathrm{N}$ have comparable influences and are positive apart from the negative local signal. This indicates that the seasonality of the southern tropical atmospheric signal of SDBM is controlled by outer biospheric zones rather than by the local vegetation. The small seasonality of the exchange flux in the intertropical band is particular to this model as already noticed in the signal simulated near Ascension Island, influenced by the African tropical savanna (Fig. 4). This is presumably due to the same influence of the soil water on NPP and $R_{H}$ which consequently makes these fluxes quite synchronous and their difference small.

In the extratropical southern zones, the latitudinal distribution of the biospheric influences on the atmospheric seasonal cycle is close to the simulated cycle in the southern tropical zones, with a progressive decrease of the amplitudes towards the South Pole and without change in the signs.

\section{Conclusion}

The comparison between the observed seasonal dynamics of atmospheric $\mathrm{CO}_{2}$ and the dynamics simulated from the TM2 transport model coupled to eight TBMs participating in the Potsdam NPP Model Intercomparison workshop provides one approach for model validation at large spatial scales. Though subject to a range of uncertainties, this approach to validation suggests the best performance from SDBM, the model calibrated to reproduce the seasonal dynamics of atmospheric $\mathrm{CO}_{2}$. Several of the prognostic models provide reasonable simulations of the north to south trend in seasonal $\mathrm{CO}_{2}$ amplitude, though most make the trend somewhat too small. This could reflect either a latitudinal distribution of NPP biased toward the tropics or too great a temporal coherence between NPP and $\mathrm{R}_{\mathrm{H}}$ at high latitudes. With the exception of SDBM, all of the TBMs have problems simulating the month of minimal $\mathrm{CO}_{2}$ concentration, especially in the southern hemisphere. The phase errors also suggest difficulties modelling the timing of NPP and $\mathrm{R}_{\mathrm{H}}$, 
especially without the constraint provided by satellite data.

In the southern hemisphere, the agreement between modelled and measured seasonal cycles of atmospheric $\mathrm{CO}_{2}$ is generally worse than in the northern hemisphere, for at least three reasons. First, the seasonal amplitude is small in the southern hemisphere, meaning that even small absolute errors are proportionally large. Second, the land area is small in the southern hemisphere, especially outside the tropics. As a consequence, transport is proportionally more important and local fluxes are proportionally less important than in the northern hemisphere. Third, fossil fuel burning and ocean fluxes have detectable contributions to the seasonality of the atmospheric signal. The influence of these fluxes is quite variable among TBMs, highlighting the diversity in estimates of seasonal tropical fluxes. These uncertainties do not allow us to validate the modelling of biospheric response to the seasonal drought stress and huge precipitation in the tropics.

While comparison with observed spatial and seasonal patterns of atmospheric $\mathrm{CO}_{2}$ cannot provide a definitive validation of a TBM, it can play a critical role in a suite of evaluation tools. Used in concert with site-based techniques, global approaches can provide a check on overall consistency, indicate areas where model performance is weak, and suggest processes that should be targets for improvements. Here, we developed a broad but largely preliminary analysis of the comparative behaviour of a large number of models. Based on this and other recent efforts, the stage is set for analyses that will tap the full power of global-scale analytical approaches for improved understanding of terrestrial NPP.

\section{Acknowledgements}

We are grateful to all the modelling teams for their active contributions, and to Chris Field for helpful discussions. Funding for this work was provided by the Programme 'European Study of Carbon in the Ocean, Biosphere and Atmosphere' (ESCOBA), contracts N Env4-CT95-0111 and Env4-CT95-0116, and by the Belgian Federal Program 'Global Change', contract CG/DD/11 A of the Office for Scientific, Technical and Cultural Affairs (OSTC) - Prime Minister's Services.

\section{References}

Andres R, Marland G, Fung I, Matthews E (1996) A one-degree-by-onedegree distribution of carbon dioxide emissions from fossil fuel consumption and cement manufacture. 1950-90. Global Biogeochemical Cycles, 10, 419-429.

Bondeau A, Kaduk J, Kicklighter D et al. (1999) Comparing global models of terrestrial net primary productivity (NPP): Importance of vegetation structure on seasonal NPP estimates. Global Change Biology, 5 (Suppl. 1), 35-45.
Ciais P, Tans PP, White JWC et al. (1995) Partitioning of ocean and land uptake of $\mathrm{CO}_{2}$ as inferred by $\delta^{13} \mathrm{C}$ measurements from the NOAA Climate Monitoring and Diagnostics Laboratory Global Air Sampling Network. Journal of Geophysical Research, 100, 5051-5070.

Conway TJ, Tans PP, Waterman LS (1994) Atmospheric $\mathrm{CO}_{2}$ records from sites in the NOAA/CMDL air sampling network. In: Trends'93: $a$ Compendium of Data on Global Change. (eds Boden TA, Kaiser DP, Sepanski RJ, Stoss FW) ORNL/CDIAC-65. Carbon Dioxide Information Analysis Center, Oak Ridge National Laboratory, Oak Ridge, TN, USA.

Cramer W, Kicklighter D, Bondeau A et al. (1999) Comparing global models of terrestrial net primary productivity (NPP): Overview and key results. Global Change Biology, 5 (Suppl. 1), 1-15.

Crutzen PJ, Bao WM, Liu MH, Lobert JM, Scharffe D (1989) Emissions of $\mathrm{CO}_{2}$ and other trace gases to the atmosphere from fires in the Tropics. In: Our Changing Atmosphere (eds Crutzen PJ, Gérard JC, Zander R). Proceedings of the 28th Liège International Colloquium, pp. 449-472.

Enting IG (1987) The interannual variation in the seasonal cycle of carbon dioxide concentration at Mauna Loa. Journal of Geophysical Research, 92, 5497-5504.

François L, Nemry B, Warnant P, Gérard JC (1996) Seasonal and interannual influences of the terrestrial ecosystems on atmospheric $\mathrm{CO}_{2}$ : a model study. Physics and Chemistry of the Earth, 21, 537-544.

Fung IY, Tucker CJ, Prentice KC (1987) Application of advanced very high resolution radiometer vegetation index to study atmosphere-biosphere exchange of $\mathrm{CO}_{2}$. Journal of Geophysical Research, 92, 2999-3015.

Gallo KP (1992) Experimental global vegetation index from AVHRR utilizing pre-launch calibration, cloud and sun-angle screening. Digital data, National Oceanic and Atmospheric Administration, National Geophysical Data Center, Boulder, Colorado, USA.

Heimann M, Esser G, Haxeltine A et al. (1998) Evaluation of terrestrial carbon cycle models through simulations of the seasonal cycle of atmospheric $\mathrm{CO}_{2}$ : first results of a model intercomparison study. Global Biogeochemical Cycles, 12, 1-24.

Heimann M, Keeling CD (1989) A three dimensional model of atmospheric $\mathrm{CO}_{2}$ transport based on observed winds. 2. Model description and simulated tracer experiments. Geophysical Monographs, 55, 237-275.

Iacobellis SF, Frouin R, Razafimpanilo H, Somerville RCJ, Piper SC (1994) North African savanna fires and atmospheric carbon dioxide. Journal of Geophysical Research, 99D, 8321-8334.

Knorr W, Heimann M (1995) Impact of drought stress and other factors on seasonal land biosphere $\mathrm{CO}_{2}$ exchange studied trough an atmospheric tracer transport model. Tellus, 47B, 471-489.

Law RM, Rayner PJ, Denning AS et al. (1996) Variations in modeled atmospheric transport of carbon dioxide and the consequences for $\mathrm{CO}_{2}$. Global Biogeochemical Cycles, 10, 783-796.

Matthews E (1983) Global vegetation and land use: new high-resolution data bases for climate studies. Journal of Climate and Applied Meteorology, 22, 474-487.

Nemry B, François L, Warnant P, Robinet F, Gérard JC (1996) The seasonality of the $\mathrm{CO}_{2}$ exchange between the atmosphere and the land biosphere: a study with a global mechanistic vegetation model. Journal of Geophysical Research, 101, 7111-7125.

Randerson JT, Thompson MV, Conway TJ, Fung IY, Field CB (1997) The contribution of terrestrial sources and sinks to trends in the seasonal cycle. Global Biogeochemical Cycles, 11, 535-560.

Ruimy A, Kergoat L, Bondeau A et al. (1999) Comparing global models of terrestrial net primary productivity: analysis of differences in light absorption and light-use efficiency. Global Change Biology, 5 (Suppl. 1), 56-64.

Russell G, Lerner J (1981) A new finite-differencing scheme for the tracer transport equation. Journal of Applied Meteorology, 20, 1483-1498.

Six KD, Maier-Reimer E (1996) Effects of plankton dynamics on seasonal carbon fluxes in an ocean general circulation model. Global Biogeochemical Cycles, 10, 559-583.

Tans PP, Thoning KW, Elliott WP, Conway TJ (1990) Error estimates of background atmospheric $\mathrm{CO}_{2}$ patterns from weekly flask samples. Journal of Geophysical Research, 95, 14063-14070. 